Heide, I. van der, Heijmans, M., Schuit, A.J., Uiters, E., Rademakers, J. Functional, interactive and critical health literacy: varying relationships with control over care and number of GP visits. Patient Education and Counseling: 2015, 98(8), 998-1004

\begin{tabular}{|l|l|}
$\begin{array}{l}\text { Postprint } \\
\text { Version }\end{array}$ & 1.0 \\
\hline Journal website & http://www.pec-journal.com/article/S0738-3991(15)00186-X/abstract \\
\hline Pubmed link & $\underline{\text { http://www.ncbi.nlm.nih.gov/pubmed/25956070 }}$ \\
\hline DOI & $10.1016 /$ j.pec.2015.04.006
\end{tabular}

This is a NIVEL certified Post Print, more info at http://www.nivel.eu

\title{
Functional, interactive and critical health literacy: Varying relationships with control over care and number of GP visits
}

\author{
IRIS VAN DER HEIDE ${ }^{\mathrm{A},}$, , MONIQUe HeIJMANs ${ }^{\mathrm{A}}$, A. JANTINE SCHUiT ${ }^{\mathrm{B}, \mathrm{C}}$, ElLEN Uiters ${ }^{\mathrm{B}}$, \\ JANY RADEMAKERS ${ }^{A}$ \\ ${ }^{a}$ NIVEL, Netherlands Institute for Health Services Research, Utrecht, Netherlands \\ ${ }^{\mathrm{b}}$ Centre for Nutrition, Prevention and Health Services, National Institute for Public Health \\ and the Environment, Bilthoven, Netherlands \\ ${ }^{c}$ Department of Health Sciences and EMGO Institute for Health and Care Research, VU \\ University Amsterdam, Amsterdam, Netherlands
}

\begin{abstract}
Objective: The aim of this study is to examine the extent to which functional, interactive and critical health literacy are associated with patients' perceived control over care and frequency of GP visits.

Methods: Data from the Dutch 'National Panel of People with Chronic Illness or Disability' was used $(N=2508)$. Health literacy was assessed by the Functional, Communicative and Critical Health Literacy measure. Perceived control over care was indicated by perceived ability to organize care, interact with providers and to perform self-care. By multivariate linear and logistic regression analyses, associations between health literacy and perceived control over care and subsequently frequency of GP visits were studied.

Results: Mainly interactive health literacy was associated with patients' perceived ability to organize care, interact with healthcare providers and perform self-care, whereas only functional health literacy was associated with number of GP visits.

Conclusion: The results imply that some patients' may be less able to exert control over their care because of lower health literacy. Functional, interactive and critical health literacy vary in their relevance for patients' ability to exert control.

Practice implications: Initiatives for strengthening patients' role in healthcare may be improved by paying attention to patients' health literacy, specifically functional and interactive health literacy.
\end{abstract}


Heide, I. van der, Heijmans, M., Schuit, A.J., Uiters, E., Rademakers, J. Functional, interactive and critical health literacy: varying relationships with control over care and number of GP visits. Patient Education and Counseling: 2015, 98(8), 998-1004

\section{INTRODUCTION}

In chronic care, patients are expected to fulfil an active role in the care of their condition, for instance by fulfilling care tasks in their home environment. This active patient role is seen as important for obtaining or maintaining the best possible state of health [1] and [2] and reducing the burden on healthcare [3] and [4]. However, previous studies imply that not all adults with chronic conditions are able to fulfil this role [5], either because they are not interested and/or because they lack the knowledge or the skills [6]. Health literacy (i.e. the ability to access, understand, appraise and apply health-related information) is considered to be relevant for this [7], [8] and [9]. Patients with higher health literacy are found to take a more active role with respect to their care [10], [11], [12] and [13] and to make less use of healthcare services than those with lower health literacy [14].

To date, most studies on health literacy have focused on functional health literacy, which reflects basic skills in reading and writing [15]. However, increasing amounts of attention are being paid to interactive/communicative and critical health literacy [15] and [16]. The terms 'interactive' and 'communicative' health literacy have both been used in literature to refer to the skills that can be used to participate actively in everyday situations, extract health information and derive meaning from different forms of health communication, and apply this to changing circumstances [15]. This includes for example searching for online health information. In the present paper, we will use the term 'interactive health literacy' to refer to these skills. Critical health literacy refers to the cognitive and social skills needed to critically assess the applicability of health information to personal situations or its reliability, such as information about the performance of healthcare providers [15]. Some consider critical health literacy to be especially relevant for individuals' ability to exert control over situations [15] and [16]. Few studies have actually addressed the relative importance of functional, interactive and critical health literacy in patients' ability to fulfil an active role in their own care [17].

If theory-driven interventions to encourage active patient participation are to be developed, it is important to obtain insights into the relationships between different types of health literacy and patients' abilities to fulfil an active role in the care for their condition. In that context, the present study will focus on health literacy in relation to patients' perceived control over the care for their illness and the frequency of their visits to the general practitioner (GP). Being able to exert a certain degree of control is considered a precondition for active patient participation and is often discussed in relation to health literacy [15], [16] and [18]. Patients' perceived control over their care is indicated in the present study by their perceived ability to perform self-care activities in the home environment, to interact effectively with healthcare providers and to organize care at the right moment [2].

In the Netherlands, a referral from the GP is required for most specialists and for hospital treatment. GPs are generally the first point of contact in healthcare when people have problems with their health. The frequency of GP visits therefore gives a good indication of the support needs of adults with chronic conditions. The association between patients' health literacy and the frequency of their GP visits will indicate whether patients with lower health literacy may need more support from their GP than patients with higher health literacy.

The literature suggests that older patients and patients who are less educated and/or less knowledgeable about their condition are more likely to have lower health 
Heide, I. van der, Heijmans, M., Schuit, A.J., Uiters, E., Rademakers, J. Functional, interactive and critical health literacy: varying relationships with control over care and number of GP visits. Patient Education and Counseling: 2015, 98(8), 998-1004

literacy, visit their healthcare provider more frequently and perceive more difficulties in exerting control over their care than younger, more highly educated and more knowledgeable patients [19], [20], [21], [22], [23] and [24]. The association between age and health literacy may in part be explained by age-related cognitive decline [25]. Furthermore, lower health literacy is associated with poorer health status and those who are in poorer health are more likely to visit their GP and to be less able to exert control over care than those who are in better health [14] and [26]. These factors will therefore be taken into account in the present study.

The objective of the current study is to obtain insights into the extent to which functional, interactive and critical health literacy relate to patients' perceived control over their care and to the frequency of their GP visits. We are specifically interested whether the three types of health literacy have differing associations with perceived control over care and frequency of GP visits. The following research questions have therefore been formulated:

1. To what extent are functional, interactive and critical health literacy associated with patients' perceived ability to perform self-care activities, interact with healthcare providers and organize care?

2. To what extent are functional, interactive and critical health literacy associated with patients' frequency of GP visits?

\section{METHOD}

\subsection{Study design and sample selection}

Data from the 'National Panel of People with Chronic Illness or Disability' (NPCD) was used. This panel is a nationwide prospective panel in the Netherlands for studying the consequences of a chronic illness or a long term disability [27]. Panel members with a chronic illness were recruited from the patient files of general practices (national random samples of general practices, drawn from the Netherlands registration of General Practice). For these panel members, general practitioners provided medical data at the time of inclusion. Panel members with a disability were recruited from national surveys. Selection criteria for chronic patients were diagnosis of a somatic chronic disease by a certified medical practitioner, aged $\geq 15$, not being institutionalized, being aware of the diagnosis, not being terminally ill (life expectancy $>6$ months according to the GP), being mentally capable of participating, and having sufficient mastery of Dutch. Disabled individuals were included when self-reported as being moderately to severely disabled. Individuals who agreed to participate filled in self-reporting questionnaires twice a year (for a maximum of four years). The NPCD is registered with the Dutch Data Protection Authority; all data was collected and handled in accordance with the privacy protection guidelines of the Authority. More detailed information on the sample selection is reported elsewhere [28]. Data for the present study was derived from panel members who filled in a questionnaire sent to them in April 2013 as well as a questionnaire sent to them in October 2013. In total, 2532 respondents returned both questionnaires. For the purpose of the present study, a selection was made of adults aged 25 or older (as the highest level of education attained is more stable after that age), which led to a final sample of 2508 adults who filled in both questionnaires. 
Heide, I. van der, Heijmans, M., Schuit, A.J., Uiters, E., Rademakers, J. Functional, interactive and critical health literacy: varying relationships with control over care and number of GP visits. Patient Education and Counseling: 2015, 98(8), 998-1004

\subsection{Assessment of the variables}

\subsubsection{Assessment of health literacy}

Health literacy was assessed by the Functional Communicative Critical Health Literacy (FCCHL) scale [29], which has been validated for the Netherlands [30] and [31]. The FCCHL is based on items that assess the frequency of perceived difficulty with functional health literacy (5 items), interactive/communicative health literacy (5 items) and critical health literacy (4 items) (see Additional File 1). Answers were given on 4-point Likert scales ranging from never perceiving difficulties (1) to often perceiving difficulties (4). Mean scores per health literacy scale were calculated by summing (inverted) item scores divided by the total number of items, resulting in a score ranging from 1 (lower health literacy) to 4 (higher health literacy). The mean scores were included in the analyses as continuous variables. A previous study based on the same data as used in the present study indicates that the three subscales measuring functional, interactive/communicative and critical health literacy can be distinguished and show good internal consistency [32].

\subsubsection{Assessment of perceived control over care}

Patients' perceived control over their care was assessed by a measure of the selfreported ability to exert control over healthcare, as assessed by a questionnaire that was developed and validated in the context of the Longitudinal Aging Study Amsterdam (LASA) study [33]. This questionnaire will in the current study be referred to as the Perceived Control over Care (PCC) scale. Three subscales were differentiated to reflect perceived ability with respect to the organization of care (8 items); interaction with healthcare providers (4 items); and self-care (4 items) (see Additional File 1). Answers on all items could be given on 5-point Likert scales ranging from 1 (not able to or with great effort) to 5 (with great ease). Mean scores were calculated per scale, resulting in a score ranging from 1 (lower ability) to 5 (higher ability). The mean scores were analysed as continuous variables.

\subsubsection{Assessment of GP visits}

Frequency of GP visits was assessed by self-reported frequency of GP visits during the last year. Because the distribution of GP visits was skewed to the right and leptokurtic, the frequency of GP visits was analysed as a dichotomous variable, using the median/mode (both equal to 4 visit) as a cut-off point.

\subsubsection{Assessment of other variables}

The following variables were included in the analyses as covariates: gender, age, level of education, perceived knowledge, cognitive functioning and health status. Self-reported age was assessed and analysed as a continuous variable. The highest completed level of education was assessed on a 7-point scale and analysed as a categorical variable with the categories low (primary school or preparatory vocational training), intermediate (intermediate or advanced general education or intermediate vocational training) and high (higher vocational education or university). Patients' perceived knowledge of their condition was assessed by a subscale of the Dutch Partners in Health Scale (PIH-Dutch) [32] which is based on two items assessing perceived general knowledge of the condition and perceived 
Heide, I. van der, Heijmans, M., Schuit, A.J., Uiters, E., Rademakers, J. Functional, interactive and critical health literacy: varying relationships with control over care and number of GP visits. Patient Education and Counseling: 2015, 98(8), 998-1004

general knowledge of medication and care of the condition (range $0=$ very little to $8=$ a great deal). The mean score for these two items was analysed as a continuous variable. Perceived cognitive functioning (one item of the EQ-6D measuring no problems with cognitive functioning; some problems with cognitive functioning; or many problems with cognitive functioning) was analysed as a dichotomous variable with the categories 'no problems with cognitive functioning' and 'one or more problems with cognitive functioning' [34]. Functional health status (10 items) and perceived general health status (5 items) were assessed by the general health scale derived from the RAND-36. Functional and perceived general health status were analysed as continuous variables on a 100-point metric ((sum scores - minimum scale score)/score range $\times 100$ ) with higher scores indicating a better state of health [35]. The type of condition (8 categories) as derived from GP records was reported as a sample characteristic.

\subsection{Missing values}

The method of multiple imputations by chained equations was used to handle the missing values in the study data [36] and [37]. Following this procedure, the original data set was imputed 20 times. The outcomes of each analysis were combined to obtain the outcome of the whole analysis, incorporating the uncertainty due to the missing values [38]. The imputations were done in $\mathrm{R} 2.14 .0$ [38] and [39].

\subsection{Statistical analysis}

As patients' ability to exert control over healthcare seems closely related to health literacy, the discriminant validity of the FCCHL and the PCC was determined by the use of exploratory factor analyses. The factor analysis was conducted based on all items of the FCCHL and PCC $(n=29)$. If the presumed subscales $(n=6)$ were reflected in the factor structure and the internal consistency of the subscales proved to be sufficient ( $\alpha \geq 0.7$ ), mean scores per subscale were calculated. Pearson's correlation coefficients were calculated between the mean scores per subscales to obtain insights into the crude associations.

To answer the research questions, associations between functional, interactive and critical health literacy (independent variables) and the perceived ability to organize care, to interact with healthcare providers, to perform self-care activities and the number of GP visits on a yearly basis (dependent variables) were estimated. Five multiple regression analyses were conducted per dependent variable, with the first model including gender, age, level of education, knowledge, cognitive functioning, self-reported general health status and self-reported functional health status. In the second model, functional health literacy was added, in the third model interactive health literacy, in the fourth model critical health literacy and in the fifth model all three types of health literacy. Linear regression modelling was used for the PCC variables and logistic regression modelling for the frequency of GP visits. The factor analyses and the regression analyses were conducted in SAS 9.3 followed by the MI procedure and the MIANALYZE procedure.

\section{RESULTS}

\subsection{Sample characteristics}

Table 1 presents the sample characteristics. The most typical respondent was female (58.4\%), aged 45 to 64 (38.4\%), attained an intermediate level of education (43.0\%) and reported no problems with cognitive functioning (70.6\%). The mean score on the 
Heide, I. van der, Heijmans, M., Schuit, A.J., Uiters, E., Rademakers, J. Functional, interactive and critical health literacy: varying relationships with control over care and number of GP visits. Patient Education and Counseling: 2015, 98(8), 998-1004

perceived knowledge scale was $6.7 \pm 1.1$, indicating that patients felt they knew a lot about their care and medications. The mean scores for perceived general health status and functional health status scales were $47.3 \pm 20.8$ and $55.2 \pm 30.2$ respectively (national scores are $70.7 \pm 20.7$ and $83.0 \pm 22.8$, respectively) [40]. With respect to the health literacy subscales, mean scores were slightly lower according to the type of health literacy, with $3.1( \pm 0.7)$ for functional health literacy, $3.0( \pm 0.7)$ for interactive health literacy and $2.6( \pm 0.8)$ for critical health literacy. With respect to perceived control over care, mean scores were again quite similar, with $3.8( \pm 0.7)$ for the organization of care, $3.7( \pm 0.8)$ for interaction with healthcare providers and 3.9 $( \pm 0.7)$ for self-care. The mean frequency of contact with the GP on a yearly basis was 5 times $( \pm 5.3)$.

\section{[TABLE 1]}

\subsection{DISCRIMINANT VALIDITY OF HEALTH LITERACY AND CONTROL OVER CARE}

The factor analysis extracted six factors (eigenvalues above 1), reflecting the theoretically presumed subscales for health literacy and control over healthcare (see Additional File 1 for the factor loadings). The Cronbach's alphas justified the calculation of sum scores for each of the six subscales of the FCCHL and the PCC ( $\alpha$ between 0.8 and 0.9 ). All subscales were significantly correlated (see Table 2).

\section{[TABLE 2]}

\subsection{Health literacy and control over care}

In separate regression models, higher functional, interactive and critical health literacy scores were associated with a higher perceived ability to organize care (see Table 3), interact with healthcare providers (see Table 4) and to perform self-care (see Table 5). The models including interactive health literacy alone accounted for more variance than the models including functional or critical health literacy alone. When including the three types of health literacy simultaneously in the regression models (the complete models), associations were no longer significant for functional health literacy with respect to perceived ability to interact with healthcare providers (see Table 4). With respect to the perceived ability to organize care and perceived ability to care for themselves, critical health literacy was no longer significant when including all three types of health literacy simultaneously in the model (see Table 3 and Table 5). The complete models accounted for $29 \%$ of the variance in perceived ability to organize care, $22 \%$ of the variance in perceived ability to interact with healthcare providers and $27 \%$ of the variance in perceived ability to care for themselves.

\section{[TABLE 3][TABLE 4][TABLE 5]}

\subsection{Health literacy and GP visits}

Functional and interactive health literacy were significantly associated with the frequency of GP visits in separate regression analyses (see Table 6). When including all three types of health literacy simultaneously in a regression model, only functional health literacy remained significantly associated with frequency of GP visits: patients with lower functional health literacy visited their GP more frequently 
Heide, I. van der, Heijmans, M., Schuit, A.J., Uiters, E., Rademakers, J. Functional, interactive and critical health literacy: varying relationships with control over care and number of GP visits. Patient Education and Counseling: 2015, 98(8), 998-1004

on a yearly basis than patients with higher functional health literacy. This last model explained $10 \%$ of the variance in GP visits.

\section{[TABLE 6]}

\section{DISCUSSION AND CONCLUSION}

\subsection{DISCUSSION}

This study adds new insights to health literacy research by showing that the variance in chronic patients' perceived control over care can be explained more by a contribution from interactive health literacy than from functional or critical health literacy. On the other hand, functional health literacy is the only type of health literacy that has a relationship with the yearly frequency of GP visits: chronic patients with lower health literacy visit their GPs more often than patients with higher health literacy. This study showed how health literacy might affect certain aspects of chronic care, which is relevant for Western countries facing the challenge of increasing numbers of people suffering from chronic diseases [41].

When it comes to patients' control over care, the present study focused on actions that refer to self-care and interaction with the healthcare system. This could in part explain the finding that critical health literacy seems less relevant for explaining differences in patients' control over their care than functional and interactive health literacy. Critical skills could become more relevant for health actions that require information to be appraised or pros and cons to be weighed up, for instance when deciding whether or not to participate in screening or deciding on care options. Future research is needed to explore whether the impact of different types of health literacy does indeed vary between specific domains and health behaviours. The findings of this study imply that patients' functional health literacy may influence their use of primary care. To our knowledge, no studies have related health literacy to the frequency of GP visits. Studies do show that patients with a lower socioeconomic position and a lower level of activation, which are both associated with health literacy, do visit their GP more often than those who have a higher socioeconomic position and level of activation [42]. Furthermore, a review of international studies shows that lower health literacy is associated with more hospitalizations and use of emergency care [14].

A plausible explanation for the association between lower functional health literacy and more GP visits would be that being unable to fully understand (written) information may lead to insecurity/lower self-efficacy, driving people to visit their GP more often. However, a recent study among Japanese diabetes patients indicates that interactive and critical health literacy rather than functional health literacy were associated with self-efficacy [17]. It could also be the case that individuals with lower health literacy are more likely to have a poorer health status than those with higher health literacy and therefore have higher rates of GP visits [11]. Our data indicated that patients with lower health literacy have poorer perceived health than patients with higher health literacy. However, our analyses were controlled for perceived functional and general health status, which implies that being in poorer health may not fully account for the association between functional health literacy and frequency of GP visits. The explanation that patients with lower functional health literacy need more support from their GP in the care for their condition than 
Heide, I. van der, Heijmans, M., Schuit, A.J., Uiters, E., Rademakers, J. Functional, interactive and critical health literacy: varying relationships with control over care and number of GP visits. Patient Education and Counseling: 2015, 98(8), 998-1004

patients with higher functional health literacy is therefore more plausible. As we cannot confirm this explanation based on our data, we suggest more research in order to obtain a better understanding of the association between lower functional health literacy and more frequent GP visits.

Additionally, future research may reveal whether GP contact is effective for patients with lower health literacy or whether other types of support could be more helpful for this group. Furthermore, future research could examine whether the associations we found with respect to GP visits are also found for other types of care, such as care by specialists or emergency care. This seems especially valuable for countries with healthcare systems that differ from the Dutch system in that they provide for direct access to specialist care.

Given the lack of clarity surrounding the interrelationships between functional, interactive and critical health literacy [15], [16], [18] and [29], the three types of health literacy were treated as distinct constructs in our analyses. Some scholars see health literacy as a hierarchical construct, in which functional skills underpin interactive/communicative skills and subsequently critical skills, providing a growing ability to exert control over situations [16] and [18]. Others see health literacy rather as a complementary set of skills [15], [16] and [29]. Our study indicates that there might not be a hierarchy within the three types of health literacy in the sense that they increasingly enable people to exert control over situations. The outcomes of the regression models show that models including interactive health literacy explain more of the variance than models that include critical health literacy. Furthermore, functional health literacy remains significantly associated with the organization of care and self-care, even after adjusting for interactive and critical health literacy. This implies that functional health literacy provides a unique contribution to these aspects of patients' control that is not covered by the other types. Our findings imply that the three types of health literacy are important for different dimensions of exerting control over care. In that respect, the functional, interactive and critical components can be seen as complementary.

Another complex relationship is the relationship between health literacy and knowledge. Some consider knowledge to be a part of health literacy. In the present study, perceived knowledge and health literacy were found to be moderately associated. Additionally, the two concepts show some overlap in the variance that they can explain in perceived control over care and frequency of GP visits. However, both concepts also provide unique contributions to explaining variation. It is therefore recommended that knowledge should be considered as covariate in future research on health literacy and health-related behaviour or health outcomes, instead of considering it to be part of health literacy. However, this approach may be dependent on the way health literacy and knowledge are operationalized. This study is subject to a number of limitations. In the first place, the questionnaires were administered in print. We have no information on non-response, but it is possible that those who have difficulty reading did not participate in the present study. This means that associations may have been underestimated and could be stronger in real life. A second limitation is that the cross-sectional design meant that no inferences could be made about the directionality of the associations that were found. Thirdly, the study was based on self-reporting of both health literacy and perceived ability to interact with healthcare providers, to perform self-care and to organize care. Self-reporting may lead to observations that differ from actual 
Heide, I. van der, Heijmans, M., Schuit, A.J., Uiters, E., Rademakers, J. Functional, interactive and critical health literacy: varying relationships with control over care and number of GP visits. Patient Education and Counseling: 2015, 98(8), 998-1004

behaviour, because respondents might give socially desirable answers or not be properly aware of their position. In a real life situation, people may have more difficulty with health literacy and exerting control over healthcare than they reported, for instance because of emotions such as stress or fear. On the other hand, people could receive help from family or friends, which may lower any adverse influences of lower health literacy on their control over care.

\subsection{CONCLUSION}

In conclusion, health literacy seems related to patients' control over their care. Interactive health literacy in particular seems relevant as a possible determinant of the extent to which patients are able to exert control over their care. The results imply that some patients may be willing but unable to engage actively in the care for their condition because of lower health literacy. Furthermore, patients with lower functional health literacy visit their GP more often, which implies that they may need more support from their GP in the care for their condition than patients with higher functional health literacy. In order to strengthen the role of patients in the care for their disease and to reduce the burden on healthcare, attention needs to be paid to health literacy both in research and in practice.

\subsubsection{Implications for practice}

In order to increase patients' engagement in their healthcare, merely focusing on functional health literacy will not be sufficient. A more effective approach may be to focus especially on patients' interactive health literacy, for instance by increasing the interaction skills of patients as well as healthcare providers. As far as we are aware, there is currently no recognized way of testing the interactive health literacy of patients during consultations. Tools that have been developed for use in practice generally address functional health literacy. An increasing amount of attention is being paid to interactive health literacy in research and so tools that do address this type of health literacy and can be used in practice may be developed in the near future. Efforts to make health-related information more accessible and understandable, for instance information about medication use, may help people take care for their conditions themselves with less support from their GPs.

\section{ACKNOWLEDGEMENTS}

This study was based on data from the research programme for the 'National Panel of people with Chronic Illness or Disability', which is financed by the Netherlands Ministry of Public Health, Welfare and Sports and the Netherlands Ministry of Social Affairs and Employment. These ministries had no role in the design and execution of the study. The authors declare that they have no competing interests.

\section{APPENDIX A. SUPPLEMENTARY DATA}

The following are the supplementary data to this article: 
Heide, I. van der, Heijmans, M., Schuit, A.J., Uiters, E., Rademakers, J. Functional, interactive and critical health literacy: varying relationships with control over care and number of GP visits. Patient Education and Counseling: 2015, 98(8), 998-1004

\section{REFERENCES}

[1] Institute of Medicine (US) Committee on Identifying Priority Areas for Quality Improvement, K. Adams, J.M. Corrigan (Eds.), Priority areas for national action: transforming health care quality, National Academies Press (US), Washington (DC) (2003)

[2] A. Coulter Patient engagement—what works? J Ambul Care Manage, 35 (2012), pp. 8089

[3] N. Begum, M. Donald, I.Z. Ozolins, J. Dower Hospital admissions, emergency department utilisation and patient activation for self-management among people with diabetes

Diabetes Res Clin Pract, 93 (2011), pp. 260-267

[4] J.M. Cramm, A.P. Nieboer Self-management abilities, physical health and depressive symptoms among patients with cardiovascular diseases, chronic obstructive pulmonary disease, and diabetes Patient Educ Couns, 87 (2012), pp. 411-415

[5] J. Kawi Predictors of self-management for chronic low back pain Appl Nurs Res, 27 (2014), pp. 206-212

[6] S.L. Swenson, S. Buell, P. Zettler, M. White, D.C. Ruston, B. Lo Patient-centered communication: do patients really prefer it? J Gen Intern Med, 19 (2004), pp. 1069-1079

[7] I. Henselmans, M. Heijmans, J. Rademakers, S. van Dulmen Participation of chronic patients in medical consultations: patients' perceived efficacy, barriers and interest in support Health Expect (2014) http://dx.doi.org.proxy.library.uu.nl/10.1111/hex.12206 [Epub ahead of print]

[8] J. Rademakers, J. Nijman, L. van der Hoek, M. Heijmans, M. Rijken Measuring patient activation in The Netherlands: translation and validation of the American short form Patient Activation Measure (PAM13) BMC Public Health, 12 (2012), p. 577

[9] K. Sorensen, S. van den Broucke, J. Fullam, G. Doyle, J. Pelikan, Z. Slonska, et al. (HLSEU) Consortium Health Literacy Project European. Health literacy and public health: a systematic review and integration of definitions and models BMC Public Health, 12 (2012), p. 80

[10] M.P. Fransen, C. von Wagner, M.L. Essink-Bot Diabetes self-management in patients with low health literacy: ordering findings from literature in a health literacy framework Patient Educ Couns, 88 (2012), pp. 44-53

[11] N.D. Berkman, S.L. Sheridan, K.E. Donahue, D.J. Halpern, A. Viera, K. Crotty, et al. Health literacy interventions and outcomes: an updated systematic review Evid Rep Technol Assess (Full Rep) (2011), pp. 1-941

[12] H. Ishikawa, E. Yano, S. Fujimori, M. Kinoshita, T. Yamanouchi, M. Yoshikawa, et al. Patient health literacy and patient-physician information exchange during a visit Fam Pract, 26 (2009), pp. 517-523

[13] J. Nijman, M. Hendriks, A. Brabers, J. de Jong, J. Rademakers Patient activation and health literacy as predictors of health information use in a general sample of Dutch health care consumers J Health Commun, 19 (2014), pp. 955-969

[14] N.D. Berkman, et al. Low health literacy and health outcomes: an updated systematic review Ann Intern Med, 155 (2011), pp. 97-107

[15] D. Chinn Critical health literacy: a review and critical analysis Soc Sci Med, 73 (2011), pp. 60-67

[16] S. Sykes, J. Wills, G. Rowlands, K. Popple Understanding critical health literacy: a concept analysis BMC Public Health, 13 (2013), p. 150

[17] M. Inoue, M. Takahashi, I. Kai Impact of communicative and critical health literacy on understanding of diabetes care and self-efficacy in diabetes management: a crosssectional study of primary care in Japan BMC Fam Pract, 14 (2013), p. 40

[18] D. Nutbeam The evolving concept of health literacy Soc Sci Med, 67 (2008), pp. 20722078

[19] R.E. Rudd Health literacy skills of U.S. adults Am J Health Behav, 31 (2007), pp. S8S18

[20] M.K. Paasche-Orlow, R.M. Parker, J.A. Gazmararian, L.T. Nielsen-Bohlman, R.R. Rudd The prevalence of limited health literacy J Gen Intern Med, 20 (2005), pp. 175-184 
Heide, I. van der, Heijmans, M., Schuit, A.J., Uiters, E., Rademakers, J. Functional, interactive and critical health literacy: varying relationships with control over care and number of GP visits. Patient Education and Counseling: 2015, 98(8), 998-1004

[21] L. Nielsen-Bohlman, A. Panzer, D.A. Kinding (Eds.), Health literacy: a prescription to end confusion, The National Academies Press, Washington, DC (2004)

[22] H.T. Nguyen, J.K. Kirk, T.A. Arcury, E.H. Ip, J.G. Grzywacz, S.J. Saldana, et al. Cognitive function is a risk for health literacy in older adults with diabetes Diabetes Res Clin Pract, 101 (2013), pp. 141-147

[23] D.W. Baker, J.A. Gazmararian, J. Sudano, M. Patterson, R.M. Parker, M.V. Williams Health literacy and performance on the mini-mental state examination Aging Ment Health, 6 (2002), pp. 22-29

[24] A.R. Dahlke, L.M. Curtis, A.D. Federman, M.S. Wolf The mini mental status exam as a surrogate measure of health literacy J Gen Intern Med, 29 (2014), pp. 615-620

[25] C. von Wagner, A. Steptoe, M.S. Wolf, J. Wardle Health literacy and health actions: a review and a framework from health psychology Health Educ Behav, 36 (2009), pp. 860877

[26] M. Rijken, M. Heijmans, D. Jansen, J. Rademakers Developments in patient activation of people with chronic illness and the impact of changes in self-reported health: results of a nationwide longitudinal study in The Netherlands Patient Educ Couns, 97 (2014), pp. 383390

[27] M. Rijken, M. van Kerkhof, J. Dekker, F.G. Schellevis Comorbidity of chronic diseases: effects of disease pairs on physical and mental functioning Qual Life Res, 14 (2005), pp. 45-55

[28] J. van der Veer, J. Joris van der Veer, G. Waverijn, P. Spreeuwenberg, M. Rijken Werk en Inkomen: kerngegevens \& trends-rapportage 2013 [Work and income: core data \& trends-report 2013] Netherlands Institute for Health Services Research (NIVEL), Utrecht (2013)

[29] H. Ishikawa, T. Takeuchi, E. Yano Measuring functional, communicative, and critical health literacy among diabetic patients Diabetes Care, 31 (2008), pp. 874-879

[30] M.P. Fransen, T.M. van Schaik, T.B. Twickler, M.L. Essink-Bot Applicability of internationally available health literacy measures in the Netherlands J Health Commun, 16 (2011), pp. 134-149

[31] R. van der Vaart, C.H. Drossaert, E. Taal, P.M. ten Klooster, R.T. Hilderink-Koertshuis, J.M. Klaase, et al. Validation of the Dutch functional, communicative and critical health literacy scales Patient Educ Couns, 89 (2012), pp. 82-88

[32] M. Heijmans, G. Waverijn, J. Rademakers, R. van der Vaart, M. Rijken Functional, communicative and critical health literacy of chronic disease patients and their importance for self-management Patient Educ Couns, 98 (2015), pp. 41-48

[33] Longitudinal Aging Study Amsterdam. Available from: http://www.lasa-vu.nl/index.htm.

[34] N.H. Hoeymans, H. van Lindert, G.P. Westert The health status of the Dutch population as assessed by the EQ-6D Qual Life Res, 14 (2005), pp. 655-663

[35] K. van der Zee, R. Sanderman Het meten van de algemene gezondheidstoestand met de RAND-36, een handleiding [Measuring general health status with the RAND-36, a guideline] Rijksuniversiteit Groningen, Noordelijk Centrum voor Gezondheidsvraagstukken, Groningen (1992)

[36] J.A. Sterne, I.R. White, J.B. Carlin, M. Spratt, P. Royston, M.G. Kenward, et al. Multiple imputation for missing data in epidemiological and clinical research: potential and pitfalls

Brit Med J, 338 (2009), p. b2393

[37] M.A. Klebanoff, S.R. Cole Use of multiple imputation in the epidemiologic literature Am J Epidemiol, 168 (2008), pp. 355-357

[38] S. van Buuren, S. Flexible Imputation of missing data Chapman \& Hall/CRC Press, Boca Raton (2012)

[39] R Development Core Team R: a language and environment for statistical computing $\mathrm{R}$ Foundation for Statistical Computing, Vienna (2008)

[40] A.L. Goud, J. de Lange, V.A. Scholtes, S.K. Bulstra, S.J. Ham Pain, physical and social functioning, and quality of life in individuals with multiple hereditary exostoses in The Netherlands: a national cohort study J Bone Joint Surg Am, 94 (2012), pp. 1013-1020

[41] E. Nolte, C. Knai, M. McKee Managing chronic conditions: experiences in eight countries World Health Organization, on behalf of the European Observatory on Health Systems and Policies, Copenhagen (2008) 
Heide, I. van der, Heijmans, M., Schuit, A.J., Uiters, E., Rademakers, J. Functional, interactive and critical health literacy: varying relationships with control over care and number of GP visits. Patient Education and Counseling: 2015, 98(8), 998-1004

[42] M. Hendriks, A.M. Plass, M. Heijmans, J. Rademakers Minder zelfmanagementvaardigheden, dus meer zorggebruik? De relatie tussen patiënt activatie van mensen met diabetes en hun zorggebruik, zorgkosten, ervaringen met de zorg en diabetes-gerelateerde klachten [Less self-management skills, so more use of care? The relationship between patient activation among people with diabetes and their use of care, healthcare costs, experiences with care and diabetes-related complaints] Netherlands Institute for Health Services Research (NIVEL), Utrecht (2013)

\section{TABLES AND FIGURES}

Table 1. : Sample characteristics $(n=2508)$.

\begin{tabular}{|c|c|c|c|}
\hline Characteristics & $\%$ & $\begin{array}{l}\text { Mean } \\
\text { (SD) }\end{array}$ & $\begin{array}{l}\text { Observed } \\
\text { range }\end{array}$ \\
\hline Female & 58.4 & & \\
\hline Age (in years) & & \begin{tabular}{|l|l|}
63.8 \\
$(13.2)$ \\
\end{tabular} & $25-93$ \\
\hline \begin{tabular}{|l|}
$<45$ \\
45 to 64 \\
65 to 74 \\
$\geq 75$
\end{tabular} & \begin{tabular}{|l|}
9.4 \\
38.4 \\
30.9 \\
21.3
\end{tabular} & & \\
\hline Dutch & 91.1 & & \\
\hline \multicolumn{4}{|l|}{ Attained level of education } \\
\hline \begin{tabular}{|l|} 
Low \\
Intermediate \\
High \\
\end{tabular} & $\begin{array}{r}34.5 \\
43.0 \\
22.5 \\
\end{array}$ & & \\
\hline Knowledge & & $6.7(1.1)$ & $0-8$ \\
\hline \multicolumn{4}{|l|}{ Cognitive functioning } \\
\hline \begin{tabular}{|l|} 
No problems \\
Some problems \\
Serious problems \\
\end{tabular} & $\begin{array}{l}70.6 \\
27.8 \\
1.6 \\
\end{array}$ & & \\
\hline Perceived general health status & & \begin{tabular}{|l|}
7.3 \\
$(20.8)$
\end{tabular} & $0-100$ \\
\hline Functional health status & & \begin{tabular}{|l}
55.2 \\
$(30.2)$ \\
\end{tabular} & $0-100$ \\
\hline \multicolumn{4}{|l|}{ Health literacy } \\
\hline \begin{tabular}{|l} 
Functional health literacy \\
Interactive health literacy \\
Critical health literacy \\
\end{tabular} & & $\begin{array}{l}3.1(0.7) \\
3.0(0.7) \\
2.6(0.8)\end{array}$ & $\begin{array}{l}1-4 \\
1-4 \\
1-4 \\
-4\end{array}$ \\
\hline \multicolumn{4}{|l|}{ Patient engagement in healthcare } \\
\hline \begin{tabular}{|l} 
Perceived ability to organize care \\
Perceived ability to interact with care \\
provider \\
Perceived ability to perform self-care $^{\mathrm{a}}$ \\
\end{tabular} & & $\begin{array}{l}3.8(0.7) \\
3.7(0.8) \\
3.9(0.7)\end{array}$ & $\mid \begin{array}{l}1-5 \\
1-5 \\
1-5\end{array}$ \\
\hline Frequency contact with GP during the last & & $5.0(5.3)$ & $0-80$ \\
\hline
\end{tabular}


Heide, I. van der, Heijmans, M., Schuit, A.J., Uiters, E., Rademakers, J. Functional, interactive and critical health literacy: varying relationships with control over care and number of GP visits. Patient Education and Counseling: 2015, 98(8), 998-1004

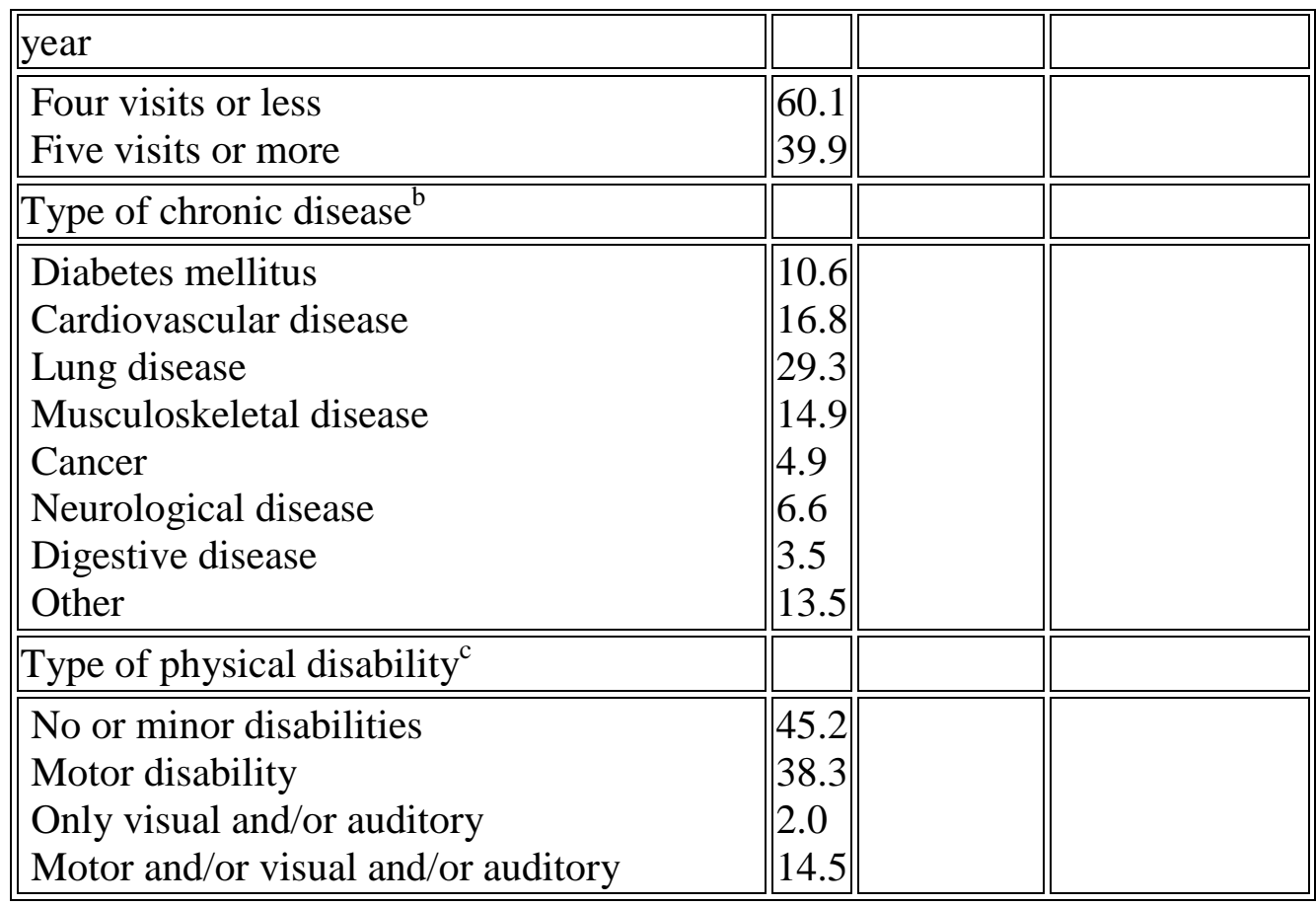

a) For two items of the self-care subscale 'not applicable' was an answer option. For respondents who filled in 'not applicable' (6\% and 11\%) mean scores were calculated based on the remaining three or two items.

b) Percentages based on respondents for which information on a chronic disease was provided based on GP records $(n=1817)$.

c) Percentage based on respondents for which information on a physical disability was reported $(n=2415)$.

Table 2. : Correlations between health literacy and control over healthcare.

\begin{tabular}{|l||l||l|l|l|l||l||}
\hline \multicolumn{1}{|l|}{} & \multicolumn{3}{|l|}{ Pearson's $r$} \\
& 1 & 2 & 3 & 4 & 5 & 6 \\
\hline \hline (1) Functional health literacy & 1 & & & & & \\
\hline \hline (2) Interactive health literacy & 0.54 & 1 & & & & \\
\hline \hline (3) Critical health literacy & 0.47 & 0.66 & 1 & & & \\
\hline (4) Organizing care & 0.33 & 0.45 & 0.34 & 1 & & \\
\hline \hline (5) Interaction with providers & 0.26 & 0.40 & 0.29 & 0.69 & 1 & \\
\hline \hline (6) Self-care & 0.27 & 0.35 & 0.27 & 0.53 & 0.49 & 1 \\
\hline
\end{tabular}

a) All correlations are significant at $p<0.0001$. 
Heide, I. van der, Heijmans, M., Schuit, A.J., Uiters, E., Rademakers, J. Functional, interactive and critical health literacy: varying relationships with control over care and number of GP visits. Patient Education and Counseling: 2015, 98(8), 998-1004

Table 3. : Outcomes multiple linear regression analyses including health literacy and perceived ability to organize care $(n=2508)$.

\begin{tabular}{|c|c|c|c|c|c|}
\hline \multirow{4}{*}{ Independent variables } & \multicolumn{5}{|c|}{ Dependent variable } \\
\hline & \multicolumn{5}{|c|}{ Perceived ability to organize care ${ }^{*}$} \\
\hline & \begin{tabular}{|l} 
Model \\
1
\end{tabular} & $\begin{array}{l}\text { Model } \\
2\end{array}$ & $\begin{array}{l}\text { Model } \\
3\end{array}$ & $\begin{array}{l}\text { Model } \\
4\end{array}$ & $\begin{array}{l}\text { Model } \\
5\end{array}$ \\
\hline & B & $\mathrm{B}$ & B & B & B \\
\hline \multicolumn{6}{|l|}{ Step 1} \\
\hline $\begin{array}{l}\text { Low educated } \\
\text { Intermediate educated (ref. high } \\
\text { educated) }\end{array}$ & $\begin{array}{l}\mathbf{- 0 . 2 0} \\
-0.05\end{array}$ & $\mid \begin{array}{l}-\mathbf{0 . 1 5} \\
-0.02\end{array}$ & $-\mathbf{0 . 1 2}$ & $\mid$\begin{tabular}{|l}
$-\mathbf{0 . 1 9}$ \\
-0.04
\end{tabular} & $-\mathbf{0 . 1 2}$ \\
\hline $\begin{array}{l}\text { Problems with cognitive } \\
\text { functioning (ref. no problems) }\end{array}$ & $-\mathbf{0 . 3 0}$ & $\mid-0.27$ & -0.24 & $\mid-0.28$ & -0.23 \\
\hline Knowledge & 0.19 & 0.17 & 0.14 & 0.16 & 0.13 \\
\hline Functional health status & 0.002 & 0.002 & 0.002 & 0.002 & 0.001 \\
\hline Perceived general health status & 0.003 & 0.003 & 0.002 & 0.003 & 0.002 \\
\hline Male & 0.01 & 0.02 & -0.01 & -0.004 & -0.002 \\
\hline Age & -0.002 & -0.0003 & 0.00002 & -0.0005 & 0.0007 \\
\hline \multicolumn{6}{|l|}{ Step 2} \\
\hline $\begin{array}{l}\text { Functional health literacy } \\
\text { Interactive health literacy } \\
\text { Critical health literacy } \\
\end{array}$ & - & $\begin{array}{l}0.17 \\
- \\
-\end{array}$ & $\begin{array}{l}- \\
- \\
-\end{array}$ & $\begin{array}{l}- \\
- \\
0.17\end{array}$ & $\begin{array}{l}0.06 \\
0.23 \\
0.04\end{array}$ \\
\hline$R^{2}$ & 0.23 & 0.25 & 0.28 & 0.26 & 0.29 \\
\hline
\end{tabular}

* Significant associations at $p<0.05$ are printed in bold.

Table 4. : Outcomes multiple linear regression analyses including health literacy and perceived ability to interact with healthcare providers $(n=2508)$.

\begin{tabular}{|c|c|c|c|c|c|}
\hline \multirow{4}{*}{ Independent variables } & \multicolumn{5}{|c|}{ Dependent variable } \\
\hline & \multicolumn{5}{|c|}{ Perceived ability to interact with providers ${ }^{*}$} \\
\hline & \begin{tabular}{|l} 
Model \\
1 \\
\end{tabular} & \begin{tabular}{|l} 
Model \\
2 \\
\end{tabular} & $\begin{array}{l}\text { Model } \\
3 \\
\end{array}$ & $\begin{array}{l}\text { Model } \\
4\end{array}$ & $\begin{array}{l}\text { Model } \\
5\end{array}$ \\
\hline & $\mathrm{B}$ & $\mathrm{B}$ & $\mathrm{B}$ & $\mathrm{B}$ & $\mathrm{B}$ \\
\hline \multicolumn{6}{|l|}{ Step 1} \\
\hline $\begin{array}{l}\text { Low educated } \\
\text { Intermediate educated (ref. } \\
\text { high educated) }\end{array}$ & $\begin{array}{l}-\mathbf{0 . 2 4} \\
-0.08\end{array}$ & $\begin{array}{l}-\mathbf{0 . 1 9} \\
-0.05\end{array}$ & $\mid$\begin{tabular}{|l}
$-\mathbf{0 . 1 5}$ \\
-0.04
\end{tabular} & \begin{tabular}{|l}
$-\mathbf{0 . 2 3}$ \\
-0.06
\end{tabular} & $\mid$\begin{tabular}{|l}
$-\mathbf{0 . 1 5}$ \\
-0.04
\end{tabular} \\
\hline $\begin{array}{l}\text { Problems with cognitive } \\
\text { functioning (ref. no problems) }\end{array}$ & -0.29 & -0.26 & -0.22 & $\mid-0.27$ & $\mid-0.21$ \\
\hline
\end{tabular}


Heide, I. van der, Heijmans, M., Schuit, A.J., Uiters, E., Rademakers, J. Functional, interactive and critical health literacy: varying relationships with control over care and number of GP visits. Patient Education and Counseling: 2015, 98(8), 998-1004

\begin{tabular}{|l|l|l|l|l|l||}
\hline \hline Knowledge & $\mathbf{0 . 1 8}$ & $\mathbf{0 . 1 7}$ & $\mathbf{0 . 1 2}$ & $\mathbf{0 . 1 5}$ & $\mathbf{0 . 1 2}$ \\
\hline \hline Functional health status & 0.00001 & -0.0005 & -0.0006 & -0.0003 & -0.0007 \\
\hline \hline Perceived general health status & $\mathbf{0 . 0 0 4}$ & $\mathbf{0 . 0 0 3}$ & $\mathbf{0 . 0 0 2}$ & $\mathbf{0 . 0 0 3}$ & $\mathbf{0 . 0 0 2}$ \\
\hline \hline Male & 0.17 & $\mathbf{0 . 1 8}$ & $\mathbf{0 . 1 5}$ & $\mathbf{0 . 1 6}$ & $\mathbf{0 . 1 6}$ \\
\hline \hline Age & $-\mathbf{0 . 0 0 4}$ & -0.002 & -0.001 & -0.002 & -0.001 \\
\hline Step 2 & & & & & \\
\hline \hline Functional health literacy & - & $\mathbf{0 . 1 6}$ & - & - & 0.03 \\
Interactive health literacy & - & - & $\mathbf{0 . 3 2}$ & - & $\mathbf{0 . 2 9}$ \\
Critical health literacy & - & - & - & $\mathbf{0 . 1 7}$ & 0.02 \\
\hline \hline $\boldsymbol{R}^{\mathbf{2}}$ & 0.16 & 0.17 & 0.22 & 0.18 & 0.22 \\
\hline \hline
\end{tabular}

* Significant associations at $p<0.05$ are printed in bold.

Table 5. :Outcomes multiple linear regression analyses including health literacy and perceived ability to perform self-care $(n=2508)$.

\begin{tabular}{|c|c|c|c|c|c|}
\hline \multirow{4}{*}{ Independent variables } & \multicolumn{5}{|c|}{ Dependent variables } \\
\hline & \multicolumn{5}{|c|}{ Perceived ability to perform self-care } \\
\hline & \begin{tabular}{|l} 
Model \\
1
\end{tabular} & \begin{tabular}{|l} 
Model \\
2 \\
\end{tabular} & \begin{tabular}{|l} 
Model \\
3 \\
\end{tabular} & \begin{tabular}{|l} 
Model \\
4 \\
\end{tabular} & $\begin{array}{l}\text { Model } \\
5\end{array}$ \\
\hline & $\mathrm{B}$ & $\mathrm{B}$ & $\mathrm{B}$ & $\mathrm{B}$ & $B$ \\
\hline \multicolumn{6}{|l|}{ Step 1} \\
\hline $\begin{array}{l}\text { Low educated } \\
\text { Intermediate educated (ref. high } \\
\text { educated) }\end{array}$ & $\mid \begin{array}{l}-0.02 \\
0.01\end{array}$ & $\mid \begin{array}{l}0.01 \\
0.02\end{array}$ & $\mid \begin{array}{l}0.03 \\
0.02\end{array}$ & $\begin{array}{l}-0.02 \\
0.01\end{array}$ & $\mid \begin{array}{l}0.03 \\
0.03\end{array}$ \\
\hline \begin{tabular}{|l} 
Problems with cognitive \\
functioning (ref. no problems)
\end{tabular} & -0.28 & -0.25 & -0.24 & -0.26 & -0.23 \\
\hline Knowledge & 0.14 & 0.13 & 0.11 & 0.12 & 0.11 \\
\hline Functional health status & 0.003 & 0.003 & 0.003 & 0.003 & 0.003 \\
\hline \begin{tabular}{|l|} 
Perceived general health status \\
\end{tabular} & 0.008 & 0.007 & 0.007 & 0.007 & 0.007 \\
\hline Male & -0.02 & -0.02 & -0.03 & -0.03 & -0.03 \\
\hline Age & 0.003 & 0.004 & 0.004 & 0.004 & 0.005 \\
\hline \multicolumn{6}{|l|}{ Step 2} \\
\hline \begin{tabular}{|l} 
Functional health literacy \\
Interactive health literacy \\
Critical health literacy \\
\end{tabular} & - & $\begin{array}{l}.12 \\
- \\
-\end{array}$ & $\begin{array}{l}- \\
-\end{array}$ & $\begin{array}{l}- \\
- \\
0.11 \\
\end{array}$ & $\begin{array}{l}\mathbf{0 . 0 5} \\
\mathbf{0 . 1 3} \\
0.03\end{array}$ \\
\hline$R^{2}$ & 0.24 & 0.25 & 0.27 & 0.26 & 0.27 \\
\hline
\end{tabular}

*Significant associations at $p<0.05$ are printed in bold. 
Heide, I. van der, Heijmans, M., Schuit, A.J., Uiters, E., Rademakers, J. Functional, interactive and critical health literacy: varying relationships with control over care and number of GP visits. Patient Education and Counseling: 2015, 98(8), 998-1004

Table 6. :Outcomes multiple logistic regression analyses including health literacy and frequency of GP visits $(n=2508)$.

\begin{tabular}{|c|c|c|c|c|c|}
\hline \multirow{4}{*}{ Independent variables } & \multicolumn{5}{|c|}{ Dependent variables } \\
\hline & \multicolumn{5}{|c|}{$\begin{array}{l}\text { Estimated odds for more than } 4 \text { GP visits on } \\
\text { a yearly basis }\end{array}$} \\
\hline & Model 1 & Model 2 & Model 3 & Model 4 & Model 5 \\
\hline & OR & OR & OR & OR & OR \\
\hline \multicolumn{6}{|l|}{ Step 1} \\
\hline $\begin{array}{l}\text { Low educated } \\
\text { Intermediate educated (ref. } \\
\text { high educated) }\end{array}$ & $\mid \begin{array}{l}1.20 \\
1.10\end{array}$ & $\mid \begin{array}{l}1.11 \\
1.06\end{array}$ & $\mid \begin{array}{l}1.15 \\
1.08\end{array}$ & $\begin{array}{l}1.19 \\
1.09\end{array}$ & $\begin{array}{l}1.10 \\
1.05\end{array}$ \\
\hline \begin{tabular}{|l} 
Problems with cognitive \\
functioning (ref. no problems)
\end{tabular} & $\mid 1.00$ & 0.95 & 0.96 & 0.98 & 0.94 \\
\hline Knowledge & 1.04 & 1.07 & 1.07 & 1.06 & 1.08 \\
\hline Functional health status & 0.99 & 0.99 & 0.99 & 0.99 & 0.99 \\
\hline Perceived general health status & 0.98 & 0.98 & 0.98 & 0.98 & 0.98 \\
\hline Male & 0.84 & 0.82 & 0.84 & 0.84 & 0.82 \\
\hline Age & 1.00 & 1.00 & 1.00 & 1.00 & 1.00 \\
\hline \multicolumn{6}{|l|}{ Step 2} \\
\hline $\begin{array}{l}\text { Functional health literacy } \\
\text { Interactive health literacy } \\
\text { Critical health literacy }\end{array}$ & - & $\begin{array}{l}0.77 \\
- \\
-\end{array}$ & $\begin{array}{ll}- \\
0.85 \\
-\end{array}$ & $\begin{array}{l}- \\
- \\
0.89\end{array}$ & $\begin{array}{l}\mathbf{0 . 7 9} \\
0.96 \\
0.98\end{array}$ \\
\hline$R^{2}$ & 0.10 & 0.10 & 0.10 & 0.10 & 0.10 \\
\hline
\end{tabular}

* Significant associations at $p<0.05$ are printed in bold. 